\title{
A Case Study on Adult and Workplace Learning
}

\author{
Sweden S. De Matas, Brendan P. Keegan \\ Office of Research Oversight, Veterans Health Administration, 810 Vermont Avenue NW (10R), Washington \\ DC 20420 , United States
}

Received: 16 October 2019; Accepted: 26 October 2019; Published: 08 February 2020

\begin{abstract}
This case study aimed to determine the effects of adult learning on employee development and performance. Specifically, the authors sought to discern whether the provision of an annual education allotment impacted employees' learning; whether the availability of a no-cost online education and training tool promoted voluntary learning and professional development; and, whether informal but mandatory workplace trainings promoted active performance-based learning and self-development. Data from a United States (US) Government office were collected and analyzed using mixed methods including quantitative and qualitative analyses. Although three different learning modalities were available, the realism was that in all learning activities, intrinsic motivation was an unavoidable paradigm that evokes and sustains effective learning, and as a result, positive job performance. In other words, a reciprocal relationship between motivation and achievement must be present to achieve and ensure continued success.
\end{abstract}

Index Terms: Adult Learning; Workplace Learning; Education; Training; Motivation; Satisfaction.

(C) 2020 Published by MECS Publisher. Selection and/or peer review under responsibility of the Research Association of Mode rn Education and Computer Science

\footnotetext{
* Corresponding author.

E-mail address:
} 


\section{Introduction and Literature Review}

Although there are many theories of learning, the most common include behaviorism, cognitive constructivism, and social constructivism [1]. Behaviorism is a passive learning style that involves repetition and positive reinforcement. Cognitive constructivism involves the active assimilation of new information and is intrinsic, goal oriented, and self-motivated. Social constructivism on the other hand is derived from societal interactions and communications; and, can be both intrinsic and extrinsic.

Less common is the theory of andragogy, a learning style for adults. Andragogy incorporates elements of cognitive and social constructivism, is problem-centered, goal oriented, practically-based, and although sometimes mandated (e.g., through an employer), usually self-initiated [2, 3]. Notably, it is a systematic and self-sustaining learning activity that is primarily based on self-motivation and commitment.

Similar to andragogy, adult workplace learning involves the acquisition and assimilation of performance-specific knowledge and skills that is also goal-oriented and practical [4]. This type of learning can be formal or informal, with formal learning relating to explicit qualifications, certified trainings, and degrees, and informal learning referring to activities such as on the job trainings, mentorships, and continuous learning activities [5]. While both formal and informal methods of workplace learning are considered equally important and complementary, the preferred method is organizationally influenced and motivated, as workplace learning is often viewed as a significant contributor to not only employees' learning, but to the organization as a whole [6].

Regardless of the theoretical application and learning modality, adult learning can be problematic with several personal and professional constraints. These may include human biology (e.g., brain degeneration), socio-economic status, age, individual levels of commitment and motivation, prior education, workplace perceptions (e.g., lack of promotional opportunities), and cost (e.g., time and money) [7, 8, 9].

Age in particular, presents a significant challenge to learning as older adults are less likely to participate in adult learning activities than their younger counterparts [10]. More specifically, adults aged 55 to 65 are three times less likely to participate in adult learning activities than adults aged 18 to 25. Likewise, adults aged 26 to 39 are one time less likely to participate than those aged 18 to 25, and adults aged 40 to 54 are two times less likely to participate in adult learning activities, than those aged 18 to 25 .

In addition to age, existing levels of education and socio-economic statuses are also highly correlated to adult learning [11]. In other words, adults who possess higher levels of education and or come from higher socio-economic backgrounds are more likely to participate in adult learning activities than those that did not. Concerning gender, and although initially considered a potential limiter, no significant differences were discerned in regard to adult learning [12]. Perhaps the most significant barrier to adult learning involves motivation and commitment with several theories pointing to a causal relationship between motivation and learning $[13,14]$. However, identifying what motivates and sustains an adult learner can be especially difficult, given the diversity of extrinsic factors.

Clearly though, adult learning activities may be both personally and professionally rewarding. Workplace learning in particular is conventionally seen as the primary method to improve job performance by enhancing required skills and knowledge. Doing so may lead to greater opportunities for employment, promotion , and career progression [15]. It may also serve to elevate levels of confidence, and self-esteem leading to higher levels of not only professional satisfaction, but also personal satisfaction [16].

This case study aimed to determine the effects of adult learning on employee development and performance. Specifically, the authors sought to discern whether the provision of an annual education allotment impacted employees' learning (Aim 1); whether the availability of a no-cost online education and training tool promoted voluntary learning and professional development (Aim 2); and, whether informal but mandatory workplace trainings promoted active performance-based learning and self-development (Aim 3). 


\section{Methodology}

\section{Background and Demographics}

This case study involved a small $(n=8)$ United States (US) Government Compliance office tasked with federal oversight of research information security programs based in 108 US healthcare facilities. 25\% of participants was female, while $75 \%$ was male. $13 \%$ was aged 26 to 39, 63\% aged 40 to 54, and 25\% aged 55 and above. $50 \%$ of all participants completed higher education beyond a Bachelor degree, 25\% received at least a Bachelor degree, and the remaining 25\% did not pursue higher education beyond high school or attained a college degree. All participants were full time, permanent, federal employees at a General Schedule (GS) [17] pay grade of at least GS-12, and as a result, socio-economic status (e.g., income, occupation) was not analyzed, although education was addressed separately.

Data Collection

\section{Aim 1 - To discern whether the provision of an annual education allotment impacted employees' learning.}

For this aim, use of an education allotment was evaluated. Each participant received an annual education allotment18 in support of ongoing education (e.g., degree and non-degree courses), professional training and development (e.g., conferences and workshops), and to be used as appropriate for job-related certifications and licenses. Data specific to this aim, was collected from the years 2015 through 2019 and included participants utilization of the provided allotments.

Aim 2 - To discern whether the availability of a no-cost online education and training tool promoted voluntary learning and professional development.

Relative to this aim, the use of an online education system was evaluated. The VA Talent Management System (TMS) is a no cost online training tool comprised of over 100,000 job-related mandatory and optional courses intended to support professional learning and development [18]. Available courses range from basic presentation and writing skills to core health (e.g., nursing) and adjunct services (e.g., Information Technology) knowledge and skills. Data specific to this aim was collected from the years 2016 through 2019 and included participant's optional use of the TMS catalog for courses other than those that were considered mandatory.

Aim 3 - To evaluate whether informal but mandatory workplace trainings promoted active performance-based learning and self-development.

Explicit to this aim and based on a needs' assessment, an informal but mandatory education program internal to the workplace was developed with the goal of growing employees' collective knowledge and required skillsets. Each aspect of the program was problem-centered, goal oriented, practically based, and designed to foster professional development in three basic but required areas identified for successful job performance (see Figure 1).

Along with the professional aspects of the program, special emphasis was also placed on personal development as built into the program were opportunities to showcase individual talent (e.g., highlighting an individual area of knowledge and/or expertise), therefore, potentially increasing personal self-esteem and confidence. 
Data related to this aim were collected from the year 2017 through 2019 and involved certain participatory action research (PAR) data points specific to the program's core tasks (e.g., problem identification, problem analysis, self-awareness, commitment, participation, and self-improvement).

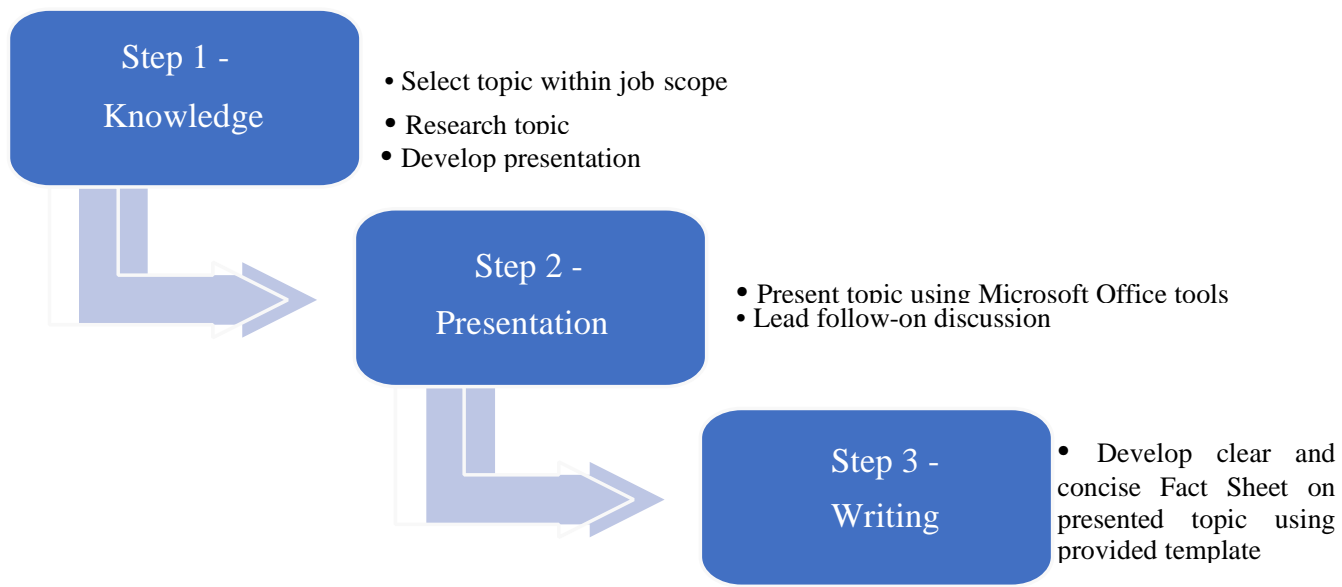

Figure 1. Internal Education Program

\section{Data Analysis}

Mixed methods were utilized including quantitative and qualitative analyses.

Quantitative analyses included frequency and percentage statistics calculated for independent groups across the outcome variables. Chi-square statistics were used to compare independent groups for age, gender, and education in regard to the annual use of the education allotment, and the online education system. Statistical significance was assumed at an alpha value of 0.05 and all analyses were conducted using the Statistical Package for the Social Sciences (SPSS).

For the internal education program and to facilitate qualitative analyses, a process consistent with PAR methodologies was used. PAR is based on the ideology that individuals should self-identify problems, determine their own development, and meaningfully problem solve [19]. Theoretically, by doing so, individuals possess the ability to positively reshape those situations that are impactful to their own personal and professional performance.

Using the PAR methodology, observational data were collected and analyzed through systematic evaluations of the internal education program submissions (i.e., required presentation documents and fact sheets), and documentation of PAR-related components (see Table 1). For example, if a participant conceptually organized their project and met all required deadlines, the commitment element was considered met or fully achieved. Conversely, if the project lacked organization or was untimely, the commitment element was considered unmet or unachieved.

Last, anecdotal evidences collected from a variety of formal and informal reciprocal participant communications regarding individual and program feedback were qualitatively analyzed using ATLAS.ti [20]. 


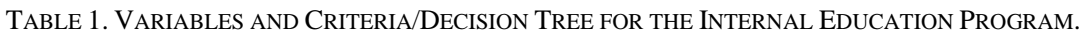

\begin{tabular}{|c|c|c|}
\hline Variables & Action & Criteria/Decision Tree \\
\hline Problem Identification & Learning vs Teaching & $\begin{array}{l}\text { Independently chose a work-related topic based on } \\
\text { self-development or planned to showcase individual } \\
\text { knowledge/skills through teaching. Measure = Yes (1) } \\
\text { or No (0) }\end{array}$ \\
\hline Commitment & Planning and Time & $\begin{array}{l}\text { Conceptually organized activities and completed the project } \\
\text { within the established time frame. Measure }=\text { Yes (1) or } \\
\text { No (0) }\end{array}$ \\
\hline Problem Analysis & Question/Issue & $\begin{array}{l}\begin{array}{l}\text { Defined the central issue, correlated the issue to } \\
\text { goals, } \\
\text { workgroup/individual } \\
\text { identified }\end{array} \\
\text { Menstraints/alternatives, and conducted topical research. } \\
\text { Measure = Yes (1) or No (0) }\end{array}$ \\
\hline Participation & Active vs Passive & $\begin{array}{l}\text { Project engagement promoted discussion and growth. Sought } \\
\text { out resources and collaborations. Responsive to feedback. } \\
\text { Measure = Yes (1) or No (0) }\end{array}$ \\
\hline Self-Awareness & $\begin{array}{l}\text { Personal Beliefs and } \\
\text { Assumptions }\end{array}$ & $\begin{array}{l}\text { Problem-solved and acknowledged/challenged personal } \\
\text { traits/ideas. } \\
\text { Measure = Yes (1) or No (0) }\end{array}$ \\
\hline Self-Improvement & Growth vs Inertia & $\begin{array}{l}\text { Constructive self-analysis of learning gaps, reciprocal } \\
\text { communications, and positive outlook to next steps. } \\
\text { Measure = Yes (1) or No (0) }\end{array}$ \\
\hline
\end{tabular}

TAble 2. Use of the Annual Education Allotment.

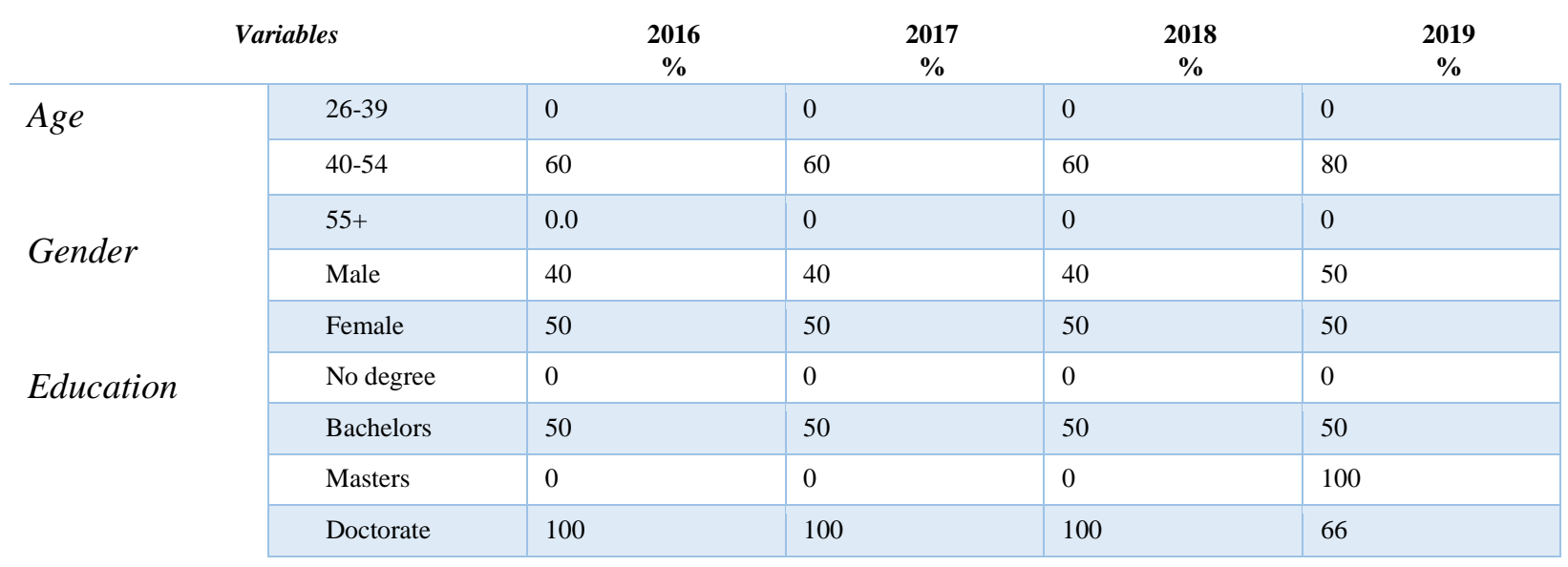

\section{Results}

Regarding the use of the annual education allotment, there were no significant differences between age groups in $2016(\mathrm{p}=0.35), 2017(\mathrm{p}=0.35), 2018(\mathrm{p}=0.35)$, and in $2019(\mathrm{p}=0.09) ; \quad$ or, $\quad$ between male and 
female participants (2016 ( $\mathrm{p}=1.0), 2017(\mathrm{p}=1.0), 2018(\mathrm{p}=1.0)$, and in $2019(\mathrm{p}=1.0)$ ). There were also no statistically significant differences between the education groups in 2016 ( $p=0.18), 2017(\mathrm{p}=0.18), 2018$ ( $\mathrm{p}=0.18$ ), and in 2019 ( $\mathrm{p}=0.34$ ); however, frequency statistics revealed that participants in the age group 40-54, and those with higher college education (i.e., doctorate) used their allotments more frequently than those in other age and education groupings (see Table 2).

With regard to the use of the no-cost online education and training tool, no statistically significant differences between age groups, gender, and education was noted. Nonetheless, for the evaluation period, frequency statistics showed that only $41 \%$ of the overall study population utilized the training system for courses other than those that were considered mandatory (see Table 3). In addition, with the exception of the first evaluated year, 2016, participation rates were routinely recorded at below $40 \%$.

TABle 3. Use of the VA TALent Management System.

\begin{tabular}{l|l|l|}
\multicolumn{2}{|c|}{ Year } & 71 \\
\hline Optional Use & 2016 & 29 \\
\hline & 2017 & 38 \\
\hline & 2018 & 25 \\
\hline
\end{tabular}

Last, for the PAR assessment relative to the internal education program, all participants met the criteria for problem identification; however, in the areas of commitment, problem analysis, and participation, only $61.9 \%$ of participants met the required criteria. In addition, only $47.6 \%$ of the study population met the established criteria for self-awareness, and $52.4 \%$ for self-improvement.

Consistent with the quantitative results, participant feedback was suffused in motivational concepts such as actions, willingness and goals. For example, participation in the various learning modalities did not necessarily result in protected time (i.e., decrease in workload), or specifically lead to immediate promotional opportunities, and as a result participants indicated and/or displayed a lack of commitment and motivation. In addition, $25 \%$ of participants cited confusion regarding the scope and goals of the internal education program and indicated an unwillingness to actively participate.

\section{Discussion and Implications}

As alluded to in the literature review, a common source of job dissatisfaction stems from the gap between required skillsets and expected performance. Recognizing the need to bridge the gap between performance and learning, while at the same time demonstrating its commitment to employees [21], and inferring a positive relationship between performance and advancement [22], a number of diverse adult learning modalities was made available to participants.

The annual education allotment, the most versatile option, removed the cost barrier and accommodated various learning styles (i.e., behavioral, cognitive, social, andragogy) and professional needs (e.g., job-related certifications and higher education). The only prerequisite to participation was intrinsic motivation and commitment for personal learning and professional development; however, for the evaluation period, only $65 \%$ of participants utilized the allotment. Of those participants, and in contrast to the existing literature, no significant correlations between age, gender, and education were identified; however, participants in the age group of 40-54, and those with higher education were more frequent users of the education allotment. 
Not dissimilar, VA TMS, the no-cost online education and training system provided learning flexibility and diversity in that participants may enroll in a variety of courses based on their own personal and professional needs, as well as availability (i.e., time). Again, the only prerequisite to participation was intrinsic motivation and commitment to self-improvement; however, for the evaluation period, only $41 \%$ of participants utilized the system for nonmandated courses. Of those participants, no significant correlations were identified regarding age, gender or education.

In contrast to the annual education allotment and the online education system, the internal education program was directly tied to job performance, and participation was mandated for the study population. Conceivably, active participation in this program may have led to elevated job-specific knowledge and skills, thus enhancing performance and satisfaction; however, active participation in the program was at a mere $64 \%$.

Although three diverse learning modalities were presented to the study population with each tailored to address individual learning styles, as well as to remove potential barriers (e.g., cost), use of and active participation in the various education programs were minimal, and without regard to age, prior education, and gender. Specific to the internal education program, participants were generally unaware of self-improvement needs and lacked motivation for ongoing learning. As a result, successful performance was mired in passivity, and personal and professional satisfaction diminished. In addition, participants indirectly applied a cost-benefit analysis to learning, meaning, if there were no perceived direct benefits to the learning (i.e., promotion), the time commitment was considered unreasonable and cost prohibitive.

Based on this case study, the realism is that in all learning activities, intrinsic motivation, is an unavoidable paradigm that evokes and sustains effective learning, and as a result, positive job performance. In other words, a reciprocal relationship between motivation and achievement must be present to achieve and ensure continued success, and positive job satisfaction [23].

\section{Conclusions}

We examined the effect of adult learning on employee development and performance. Using quantitative and qualitative analyses, we were unable to identify significant correlations in adult learning with age, gender, or education, relative to this study population, but was able to identify individual motivation and self-commitment as key factors to individual and professional success. Specifically, an employee's ability to positively reshape those situations that are impactful to their personal and professional development is dependent on their own levels of motivation and commitment (e.g., ability to self-identify problems, determine a development path, meaningfully problem solve), regardless of the provided tools (i.e., allotment, online system, internal education program).

\section{Limitations}

Data were derived from a single workplace program; therefore, the results are based solely on the observations and activities; and, the conclusions have limited applicability to that or similar programs. In addition, and although not analyzed, but of merit, $75 \%$ of all participants were classified as virtual employees (i.e., primary place of employment was their home). Potentially, this classification may contribute to a lack of cohesiveness and camaraderie, and as a result, diminished messaging on performance and learning. 


\section{Acknowledgements}

The authors wish to thank the Department of Veterans Affairs for its support in this project; however, it should be noted that the views presented in this article are those of the authors and do not necessarily represent the views of the Department of Veterans Affairs.

\section{References}

[1] Ormrod, J. (2012). Human learning (6th ed.). Boston: Pearson

[2] Merriam, S. and Brockett, R. (2007). The Profession and Practice of Adult Education: An Introduction. Jossey-Bass.

[3] Spencer, Bruce (2006). The purposes of adult education: a short introduction (2nd ed.). Toronto: Thompson Educational Publishing.

[4] Cacciattolo, K. (2015). Defining workplace learning. European Scientific Journal, May 2015.

[5] Crouse, P., Doyle, W., and Young, J. (2011). Workplace learning strategies, barriers, facilitators and outcomes: a qualitative study among human resource management practitioners. Human Resource Development International, 14(1).

[6] See Crouse, P., et al (2011).

[7] Kunga, K., and Machtmes, K. (2009). Lifelong learning: Looking at triggers for adult learning. The International Journal of Learning, 16(7), 501-511.

[8] Bariso, E. (2008). Factors affecting participation in adult education: a case study of participation in Hackney and Waltham Forest, London. Studies in the Education of Adults. 40. 110-124.

[9] Chang, D. (2012). Adults Engaged in Lifelong Learning: Analysis by Gender and Socioeconomic Status. Australian Journal of Adult Learning, 52. 310-336.

[10] Chrisholm, L., Larson, A. and Mossoux, A. (2004). Lifelong learning: Citizen' views in close up: Findings from a dedicated Eurobarometer survey, CEDEFOP. Office for Official Publications of the European Communities Luxembourg.

[11] Bohonos, J. (2014). Understanding Career Context as a Key to Recruiting, Retaining and Best Serving Adult Students. Journal of Adult Learning.

[12]Kim, K., Hagedorn, M., Williamson, J., and Chapman, C., (2004). Participation in adult education and lifelong learning: 2000-01. National Center for Education Statistics.

[13] See Ormond, J. (2012); Merriam, S. et al (2007; Spencer, B. (2006); and, Cattiattolo, K. (2015).

[14] Olusegun, A. (2015). Motivating Factors for Adult Learners in Higher Education. International Journal of Higher Education, 4(1).

[15] Mundo, J. (nd). Adult education has long-term impact on the economy and society at large. European Association for the Education of Adults (EAEA). Mundo-J. Retrieved March 15, 2019.

[16] Schmidt, S. W. (2010). The Relationship between Job Training and Job Satisfaction: A Review of Literature. International Journal of Adult Vocational Education and Technology (IJAVET), 1(2), 19-28.

[17]See https://www.opm.gov/policy-data-oversight/pay-leave/salaries-wages/2019/general-schedule/. 18 Average of $\$ 3000.00$ annually.

[18] https://www.valu.va.gov/Home/TMSResources

[19] Reason, P. and Bradbury, H. (2008) (eds). The Sage Handbook of Action Research: Participative Inquiry and Practice. Sage, CA

[20]https://atlasti.com/

[21]Kim, Jim Yong. (2018). “The Human Capital Gap: Getting Governments to Invest in People.” Foreign Affairs (July/August). 
[22]World Bank (2019). World Development Report 2019: The Changing Nature of Work. Washington, DC: World Bank.

[23]Rotgans, J. and Schmidt, H. (2012). The Intricate Relationship Between Motivation and Achievement: Examine the Mediating Role of Self-Regulated Learning and Achievement-Related Classroom Behaviors. International Journal of Teaching and Learning in Higher Education, 24(2).

\section{Author's Profile}

Sweden S. De Matas, PsyD; Corresponding author. Office of Research Oversight, Veterans Health Administration, 810 Vermont Avenue NW (10R), Washington DC 20420

Brendan P. Keegan, PhD; Coauthor. Office of Research Oversight, Veterans Health Administration, 810 Vermont Avenue NW (10R), Washington DC 20420

How to cite this paper: Sweden S. De Matas, Brendan P. Keegan, " A Case Study on Adult and Workplace Learning ", International Journal of Education and Management Engineering(IJEME), Vol.10, No.1, pp.11-19, 2020.DOI: 10.5815/ijeme.2020.01.02 